\title{
Topical Delivery of Hyaluronic Acid into Skin using SPACE- peptide Carriers
}

\author{
Ming Chen ${ }^{1}$, Vivek Gupta ${ }^{1,2}$, Aaron C. Anselmo ${ }^{1}$, John A. Muraski ${ }^{3,{ }^{*}}$, and Samir Mitragotri ${ }^{1,{ }^{*}}$ \\ ${ }^{1}$ Department of Chemical Engineering, Center for Bioengineering, University of California, Santa \\ Barbara, CA 93106 \\ ${ }^{3}$ Convoy Therapeutics
}

\begin{abstract}
Topical penetration of macromolecules into skin is limited by their low permeability. Here, we report the use of a skin penetrating peptide, SPACE peptide, to enhance topical delivery of a macromolecule, hyaluronic acid (HA, MW: 200-325 kDa). The peptide was conjugated to phospholipids and used to prepare an ethosomal carrier system ( 110 nm diameter), encapsulating HA. The SPACE-ethosomal system (SES) enhanced HA penetration into porcine skin in vitro by 7.8+/-1.1-fold compared to PBS. The system also enhanced penetration of HA in human skin in vitro, penetrating deep into the epidermis and dermis in skin of both species. In vivo experiments performed using SKH1 hairless mice also confirmed increased dermal penetration of HA using the delivery system; a 5-fold enhancement in penetration was found compared to PBS control. Concentrations of HA in skin were about 1000-fold higher than those in blood; confirming the localized nature of HA delivery into skin. The SPACE-ethosomal delivery system provides a formulation for topical delivery of macromolecules that are otherwise difficult to deliver into skin.
\end{abstract}

\section{Keywords}

Topical; Hyaluronan; healing; wound; repair; wrinkle

\section{Introduction}

Skin is the largest organ of the human body, which covers a surface area between 1.5 2.0 $\mathrm{m}^{2}$. From a pharmaceutical point of view, skin offers an outstanding route for therapeutic delivery with several advantages over other means of administration, including avoidance of first-pass metabolism, sustained and controlled delivery over a prolonged period of time, potential access to either local or systemic target sites and improved patient compliance [1,

(C) 2013 Elsevier B.V. All rights reserved.

“To whom correspondence should be addressed: Prof. Samir Mitragotri (samir@engineering.ucsb.edu) or Dr. John A. Muraski (jmuraski@ convoytx.com).

${ }^{2}$ Current Address. School of Pharmacy, Keck Graduate Institute of Applied Life Sciences, 535 Watson Dr., Claremont, CA 91711

Publisher's Disclaimer: This is a PDF file of an unedited manuscript that has been accepted for publication. As a service to our customers we are providing this early version of the manuscript. The manuscript will undergo copyediting, typesetting, and review of the resulting proof before it is published in its final citable form. Please note that during the production process errors may be discovered which could affect the content, and all legal disclaimers that apply to the journal pertain. 
2]. Over the past three decades, transdermal drug delivery has become one of the most successfully used alternate routes for drug delivery [3]. Skin also represents a commonly sought-after target for local delivery of drugs for treatment of various diseases including psoriasis, cancer and skin infections. According to a recent report from the Pharmaceutical Research and Manufacturers of America (PhRMA), US biopharmaceutical research companies are currently developing nearly 300 products for skin diseases to help more than 100 million patients, one third of the U.S. population, that suffer from at least one skin disease [4].

The range of drugs delivered through the skin, either for systemic or for local applications, however, has been very narrow owing to skin's barrier properties characterized by low permeability $[5,6]$ which restricts the use of transdermal delivery to hydrophobic drugs with molecular weights less than 500Da [7]. However, an increasing number of biopharmaceuticals and macromolecules, such as peptides, proteins, nucleic acids, vaccines, polysaccharides and siRNA are being developed for therapeutic, medical and personal care applications, which are difficult to deliver by conventional means [8].

Skin penetrating peptides offer a potential means to enhance dermal/transdermal delivery of macromolecules. A variety of peptides such as TAT, polyarginine, meganin, penetratin, TD-1 and SPACE-peptide have been identified for this purpose [9-14]. SPACE-Peptide was discovered through phage display and was shown to deliver siRNA and streptavidin into skin after direct chemical conjugation [13]. While chemical conjugation of SPACE peptide with the cargo demonstrates the feasibility of the approach, the conjugation process also poses certain hurdles. Specifically, the conjugation process requires chemical modification of the cargo which could alter its chemical, biological and pharmaceutical properties. In addition, conjugation may not be feasible for certain drugs, thus limiting the applicability of the peptide as an enhancer.

Here, we demonstrate that the previously published SPACE-peptide can be used as a part of a lipid-based carrier system encapsulating and delivering macromolecular cargoes without chemical conjugation. Specifically, we demonstrate the utility of a SPACE-lipid carrier system, referred to as SES (SPACE-Ethosomal System), to deliver a hydrophilic macromolecule, Hyaluronic Acid (HA). HA is a hydrophilic dipolysaccharide with a very high molecular weight (200kDa 325kDa in this study). HA has been used for a wide variety of medical applications including osteoarthritis [15], embryo implantation [16], and cutaneous wound healing $[17,18]$. In dermatology and cosmetic practice, HA has been employed to help the skin to regain elasticity, turgor and moisture [19]. HA is a major component of the skin extracellular matrix and is involved in various biologic processes such as hydration, nutrient exchange, and cell differentiation and motility [19]. Owing to its high molecular weight and charge, HA is a difficult molecule to deliver into the skin and represents an excellent model molecule to test the capabilities of SPACE-based carrier systems to enhance skin penetration. 


\section{Materials and methods}

\section{Chemicals}

Phospholipon 90G (Phosphatidylcholine 94.4\%, Lysophophatidylcholine 2.5\%, Non-polar lipids $1.5 \%$, tocopherol $0.2 \%$, ethanol $0.1 \%$, water $0.4 \%$ ) was a gift from Lipoid LLC (Newark, NJ, USA). POPE-NHS (COATSOME® FE-6081SU5, N-(Succinimidyloxyglutaryl)-L-a-phosphatidylethanolamine, 1-Palmitoyl-2-oleoyl) was purchased from NOF America Corporation (White Plains, NY, USA). SPACE peptide (AC-TGSTQHQ-CG, Disulfide Bridge 2-10) was purchased from Ambiopharm (North Augusta, SC, USA) and Bachem (Torrance, CA, USA). Fluorescein-labeled SPACE-peptide (FITC-AC-TGSTQHQCG, Disulfide Bridge 2-10) was purchased from RS Synthesis, LLC (Louisville, KY, USA). Fluorescein-labeled linear Hyaluronic acid (F-HA, Mw 200-325kDa) was purchased from Creative PEGWorks (Winston Salem, NC, USA).

\section{Conjugation of SPACE-Peptide with lipid}

A solution of SPACE peptide in PBS (pH 8.0) was incubated with a solution of POPE-NHS in ethanol (PBS: ethanol, 1:1, V/V) at room temperature for $2 \mathrm{hrs}$. The efficiency of conjugation of SPACE peptide with POPE-NHS was determined by TNBS $(2,4,6-$ trinitrobenzene sulfonic acid) method [20]. TNBS interacts with primary amino group of the peptide to generate a highly chromogenic product which can be readily measured at $335 \mathrm{~nm}$.

\section{Preparation of Ethosomal systems}

All liposomal systems were prepared by a conventional rotary evaporation method [21]. Briefly, the appropriate mass of Phospholipon 90G was dissolved in ethanol. In case of SPACE-liposomal combination system, the lipid solution was added to SPACE-PeptidePOPE conjugation solution. The solvent was removed using a rotary evaporator at room temperature. The resultant dry lipid films on the inside wall of the round bottom flask were hydrated and dispersed with the hydration systems containing $1 \mathrm{mg} / \mathrm{mL} \mathrm{HA}$ at room temperature. The resultant ethosomal solution was extruded 21 times through a $100 \mathrm{~nm}$ polycarbonate membrane (AVESTIN, Inc., Ottawa, ON, Canada) using a mini-extruder (LiposoFast, AVESTIN, Inc, Ottawa, ON, Canada) at room temperature. Unreacted SPACE peptide was not removed from the formulation since small amounts of peptide are unlikely to have a significant impact on skin penetration.

\section{Characterization of Ethosome preparations}

The particle size, polydispersity index (PDI) and $\zeta$-potential of the liposomal systems were determined by photon correlation spectroscopy (Zetasizer Nano series, Malvern Instruments Ltd., Worcestershire, UK). Before the size and $\zeta$-potential measurements, different liposome samples were diluted 100-times with distilled de-ionized water (EMD Millipore, Billerica, MA, USA). Measurements were made at $25^{\circ} \mathrm{C}$ with a fixed angle of $137^{\circ}$. Sizes quoted here are the $\mathrm{z}$-average means for the liposomal hydrodynamic diameter [22]. PDI from photon correlation spectroscopy was defined as the scaled ratio of the second the first order coefficients describing the distribution decay rates and span a range of 0 to 1[23]. Calculation of $\zeta$-potential $(\mathrm{mV})$ was performed using electrophoretic mobility [24]. 


\section{Skin penetration study in vitro}

Full thickness pig skin (Lampire Biological Laboratories, Pipersville, PA) and full thickness abdomen human skin (National Human Tissue Resource Center, Philadelphia, PA) were used in this study. All skin samples were stored at $-80^{\circ} \mathrm{C}$ and defrosted immediately prior to use. Briefly, the skin was allowed to thaw with the stratum corneum (SC) side up for at least half an hour at room temperature. Skin disks of $36 \mathrm{~mm}$ diameter were punched out. The subcutaneous fatty tissue was carefully removed from the dermis. In the case of pig skin, the hair shaft was cut off to no more than $4 \mathrm{~mm}$. The skin pieces were cleaned with PBS (pH 7.4) and the integrity of these pieces was determined by measuring the skin conductivity [25] to ensure that the samples were free from surface defects.

In vitro skin penetration and deposition experiments of different test formulations containing HA were performed in Franz diffusion cells under occlusive conditions at $37 \pm 1^{\circ} \mathrm{C}$. The effective penetration area and receptor cell volume were $1.77 \mathrm{~cm}^{2}$ and $12.0 \mathrm{~mL}$, respectively. The receptor compartment was filled with PBS at $\mathrm{pH}$ 7.4. Each test formulation was assessed in triplicate. Skin was mounted with the SC side up and the donor compartment was left dry and open to atmosphere for 0.5 hour before applying the test formulation. Caution was taken to remove all air bubbles between the underside of the skin (dermis) and the receptor solution. In addition, the skin was stretched in all directions to minimize the presence of furrows. $200 \mu \mathrm{L}$ of the test formulation was applied to skin surface using a pipette. The incubation time of the skin with different test formulations was $24 \mathrm{~h}$. At the end of the experiment, a $1 \mathrm{~mL}$ sample was withdrawn from the receptor compartment, and the concentration of HA was determined using a micro-plate reader (SAFIRE, XFLUOR4, V4.50, Tecan Group Ltd, NY, US). The formulations were removed from the skin by washing five times with PBS ( $\mathrm{pH}$ 7.4). The skin was transferred onto a device for tape-stripping the SC.

\section{Extraction of HA from skin layers}

The SC was removed by striping with an adhesive tape (Scotch® Transparent Tape, 3M Corporation, St. Paul, MN). In order to avoid impact of furrows, the skin was stretched and mounted on cork discs. The skin was covered with a Teflon mask with a central hole of 15 $\mathrm{mm}$ in diameter. Each tape was put onto the skin and a weight of $2 \mathrm{~kg}$ was placed on the tape for 10 seconds. The tape was quickly removed with forceps and transferred into a glass vial of suitable size. Ten stripping procedures were performed consecutively. The stripped tapes were collected in glass vials according to the following scheme: vial $1=1^{\text {st }}$ strip, vial $2=2^{\text {nd }}$ through $5^{\text {th }}$ strips and vial $3=6^{\text {th }}$ through $10^{\text {th }}$ strips. After tape-stripping, the epidermis sheet was separated from the dermis with a sterile surgical scalpel and cut into small pieces and collected into a glass vial. The dermis was cut into small pieces and transferred into a glass vial. For extraction of HA from the separated skin layers, $4 \mathrm{~mL}$ of methanol and PBS pH $7.4(1: 1, \mathrm{~V} / \mathrm{V})$ mixture was added to each glass vial. The vials were shaken overnight at room temperature. Afterwards the dispersions were centrifuged (10 minutes, $10000 \mathrm{rpm}$ ) to pellet skin tissue pieces at the bottom. The supernatants were withdrawn, diluted if necessary, and HA concentrations were determined by fluorescence spectroscopy. Fluorescence detection was performed at an excitation of $485 \mathrm{~nm}$ and an 
emission of 520nm. The method was validated for linearity, accuracy and precision. The linear range during the measurements was from $0.01 \mu \mathrm{g} / \mathrm{mL}$ to $10 \mu \mathrm{g} / \mathrm{mL}\left(\mathrm{r}^{2}=0.9999\right)$.

\section{Confocal Microscopy}

The skin samples were harvested and then immediately frozen in OCT compound and sectioned at a thickness of $20 \mu \mathrm{m}$ on a cyrotome (Leica). After sectioning, the tissues were mounted on a glass slide (Fisher Scientific). $30 \mu \mathrm{L}$ of Permount mounting medium (Fisher Scientific) was placed on top of the skin section along with a glass cover slip to seal slides. All samples were imaged on a confocal microscope (Leica and Olympus Fluoview 1000, Olympus America, PA, USA). The confocal microscopy system parameters were kept constant for all measurements in order to allow for comparison.

\section{Skin penetration in vivo}

The efficacy of SPACE-ethosomes combination system in enhancing transport of HA was tested in SKH1-hr strain of hairless inbred mice (Charles River Laboratories, 8 weeks old) according to protocols approved by the Institutional Animal Care and Use Committee. Briefly, a cylinder with an exposed skin area of $1.8 \mathrm{~cm}^{2}$ was attached to the back of anesthetized animals using minimal Vetbond ${ }^{\circledR}$ tissue glue (3M Corporation, St Paul, MN), and $100 \mu \mathrm{L}$ of the test solution containing $1 \mathrm{mg} / \mathrm{mL}$ of HA was topically applied to the exposed skin area. Following addition of the solution to the cylinder, the solution was manually spread over the entire exposed area. The cylinder was covered with parafilm to prevent evaporation. Animals were kept under constant minimal anesthesia in an anesthesia chamber placed on a heating pad so as to avoid hypothermic reactions. During the entire duration of experiments, animals were closely monitored for vital parameters. After 6hrs, animals were sacrificed with $\mathrm{CO}_{2}$ overexposure, and skin biopsy ( $5 \mathrm{~mm}$ diameter) and blood samples from cardiac puncture were collected. Skin samples were homogenized and tested for fluorescence intensity to quantify total amount delivered into the skin. For blood samples, Ethylenediamine tetra acetic acid disodium salt was added as an anticoagulant. The blood was separated into plasma and cells by centrifugation at $1200 \times \mathrm{g}$ for $15 \mathrm{~min}$. HA concentrations in plasma were determined by fluorescence spectroscopy. Fluorescence detection was performed at an excitation of $485 \mathrm{~nm}$ and an emission of $520 \mathrm{~nm}$. The linear range during the measurements was from $0.01 \mu \mathrm{g} / \mathrm{mL}$ to $1 \mu \mathrm{g} / \mathrm{mL}\left(\mathrm{r}^{2}=0.9999\right)$. Four mice were used for each test formulation group.

\section{Measurements of Partition Coefficient}

The partition coefficient of SPACE-peptide in epidermis or dermis was measured with a modified shake-flask method [26]. Briefly, the pig stratum corneum/epidermis membranes were separated from dermis by the heat separation technique [27]. A known mass of SC/ epidermis or dermis was immersed in a PBS (pH 7.4) solution containing $0.25 \mathrm{mg} / \mathrm{mL}$ of FITC-SPACE-peptide in a glass vial at $37^{\circ} \mathrm{C}$ for 48 hours. Afterwards, the supernatants were withdrawn, diluted and analyzed for final concentration in donor PBS solution by fluorescence spectroscopy. The concentration of FITC-SPACE in SC/epidermis or in dermis was calculated from the mass of peptide disappearing from the solution divided by the volume (mass) of the tissue. The partition coefficient of SPACE-peptide between PBS and SC/epidermis or that between PBS and dermis was calculated as the ratio of peptide 
concentration in the tissue divided by the peptide concentration in the solution. Fluorescence detection was performed as described above. The linear range during the measurements was from $0.01 \mu \mathrm{g} / \mathrm{mL}$ to $1 \mu \mathrm{g} / \mathrm{mL}\left(\mathrm{r}^{2}=0.9999\right)$

\section{Data analysis}

All reported data are mean \pm SD. Statistical significance was assessed by the two-tailed and unpaired Student's t-test in Microsoft Excel. The level of significance was set at $p<0.05$, unless otherwise indicated.

\section{Results}

The preparation protocol yielded SPACE-decorated ethosomes (Fig. 1) with a mean diameter of $110 \mathrm{~nm}$ and a zeta potential of about $-40 \mathrm{mV}$. The size is consistent with the pore size of the extrusion membrane $(100 \mathrm{~nm})$.

The negative charge originates primarily from the negatively charged lipids and also likely from HA. The efficiency of conjugation between SPACE-peptide and POPE-NHS was greater than $90 \%$. Unconjugated SPACE-peptide was not removed from the SES formulations.

The SPACE-ethosomal system (SES) significantly enhanced penetration of HA into skin (Fig 2a); 9.3\% $\pm 1.2 \%$ of applied HA from the SES formulation penetrated into skin over 24 hours. This penetration was 7.8 \pm 1.1 -fold $(p<0.01)$ higher than that from PBS, $5.9 \pm 2.5$-fold $(p<0.01)$ higher than that from 1:1 PBS:Ethanol control and 3.2 \pm 0.6 -fold $(p<0.01)$ higher than that from ethosomes without SPACE-Peptide. The SES formulation also increased the penetration depth of HA into skin; $3.3 \% \pm 0.6 \%$ of the applied dose penetrated into the epidermis, which is approximately 10 -fold $(p<0.01)$ higher than that observed with PBS alone (Fig. 2b). The SES formulation also significantly enhanced HA penetration into the SC $(p<0.01)$ (Fig. 3). In contrast, the accumulation of HA in the dermis or the receptor phase was not significantly different between the SES formulation and PBS control $(p>0.05)$. Thus, while the SES formulation enhanced HA skin penetration, delivery was localized in various skin layers.

The magnitude of enhancement of HA penetration induced by the SES formulation was dependent on the concentration of SPACE peptide (Fig. 4a). Noticeable penetration (3.4\% $\pm 0.5 \%$ of applied dose) was observed at a SPACE peptide concentration of $2 \mathrm{mg} / \mathrm{mL}$. Penetration further increased to $9.3 \% \pm 1.2 \%$ when the concentration of SPACE peptide increased to $5 \mathrm{mg} / \mathrm{mL}(p<0.01)$. A further increase in SPACE concentration to $10 \mathrm{mg} / \mathrm{mL}$, however, did not lead to a proportional increase in penetration $(6.9 \% \pm 0.7 \%)$. The optimum concentration of SPACE peptide in the SES formulation was thus deemed to be $5 \mathrm{mg} / \mathrm{mL}$.

HA penetration efficacy was also found to be $\mathrm{pH}$ dependent (Fig. 4b). As pH of the SES formulation increased from 4 to 8 , the delivery of HA into skin decreased significantly $(2.6 \% \pm 0.4 \%$ at $\mathrm{pH} 8$ compared to $9.3 \% \pm 1.2 \%$ at $\mathrm{pH} 4 p<0.01)$. No such dependence of penetration on $\mathrm{pH}$ was found in case of controls $(1.5 \% \pm 0.2 \%$ at $\mathrm{pH} 8$ and $1.2 \% \pm 0.2 \%$ at $\mathrm{pH}$ $4, p>0.05)$. 
The efficacy of the SES formulation in HA delivery was also tested in human skin (Fig. 5). Delivery of HA using the SES formulation in human skin was comparable to that observed in porcine skin ( $p>0.05$ ). Penetration depth of HA into human skin was assessed using confocal microscopy (Fig. 6). Deep penetration of HA into the dermis was observed when delivered via SES compared to controls.

Enhanced skin penetration of HA using the SES formulation was also observed in vivo in mice. The skin deposition of HA from this formulation after a 6-hour contact $(4.5 \% \pm 1.6 \%)$ was significantly enhanced, which is $5.1 \pm 1.8$-fold $(p<0.01)$ higher than that from PBS control $(0.9 \% \pm 0.06 \%)$ (Fig.7a). In addition, concentrations of HA in local skin tissue under the application site were about 1000-fold $(p<0.01)$ higher than those in systemic circulation, indicating HA primarily accumulated in mouse skin located under the application area (Fig. 7b). Confocal microscopy studies confirmed deep penetration of SES-formulated HA in mouse skin (Fig. 7d). Meanwhile, in PBS controls, relatively low penetration of HA was observed (Fig. 7c).

The physical stability of the SES HA formulation was investigated at $4^{\circ} \mathrm{C}$ for 4 weeks in terms of particle size distribution (Fig. 8a,b) and $\zeta$-potential (Fig. 8c). The formulation exhibited low polydispersity index $(\mathrm{PDI})$ values (PDI $<0.2$ ), indicating that it was a homogeneous suspension. However, the particle size distribution and $\zeta$-potential of the system changed gradually over 4 weeks (from $110.1 \pm 2.3 \mathrm{~nm}$ to $133.6 \pm 6.7 \mathrm{~nm}$ and from $-36.7 \pm 0.8 \mathrm{mV}$ to $-48.6 \pm 1.3 \mathrm{mV}$, respectively). The long term stability of SES formulation should be explored in future studies.

\section{Discussion}

The study demonstrates the use of a formulation containing a skin and cell penetrating peptide, SPACE-peptide, to improve dermal absorption of HA. Previous studies with SPACE peptide were reported using direct chemical conjugation of SPACE peptide with the active cargo [13]. The present study eliminates that constraint by using lipid vesicles as a means to display SPACE peptide and encapsulate the active cargo.

Liposomes have been used for dermal delivery applications for more than three decades [28, 29]; however, their efficacy in delivering drugs has been found to depend on the composition and the choice of drug [30-33]. Several specific modifications of liposomal compositions have been proposed to improve their efficacy. These include addition of ethanol to prepare ethosomes [34-38] or incorporation of sodium cholate, Tween 80, sodium deoxycholate or other surfactants to make deformable liposomes [39-42]. Ethosomes have been used to deliver various small and large molecules across the skin including testosterone bacitracin [36], and 5-fluoraracil [43]. In this study, an ethosome-like system was used as the preferred vehicle in view of their previous success in topical delivery.

In vitro results confirm that the SPACE-ethosomal (SES) formulation enhances penetration of HA into skin. In particular, significant penetration of HA into epidermis was observed compared to controls. Relatively minimal penetration into dermis and limited penetration into the receptor compartment was found. Topical delivery of HA has been of significant 
interest, although relatively few studies have systematically measured the penetration profile of HA. Brown et al studied penetration of tritium-labeled HA (MW: 250-400 kDa) into mouse and human skin from gels, demonstrating HA is transported across the epidermis and metabolized in the skin [44]. Permeation of HA tetrasaccharides through hairless mouse skin has also been studied in vitro and in vivo [45]. These studies reported low penetration of HA through intact skin; however, a significant effect of HA was found on epidermal healing in response to UV-induced skin damage. Clinical studies have also been performed to assess the effect of topical application of HA formulations on skin appearance. One study assessed the effect of various molecular weight HA (50-2000kDa) and reported that 50 and $130 \mathrm{kDa}$ HA induced significant improvement in skin elasticity and roughness compared to placebo [46]. Topical HA has also been shown to be effective for wound healing applications. Specifically, topical application of HA has been shown to activate TLR2 and TLR4 and eventually lead to increased self-defense of skin epithelium by induction of beta defensin [47].

Dermal penetration of HA in the SES formulation likely originates from the synergistic action of SPACE peptide, ethanol and lipid vesicles. Ethanol in itself is a penetration enhancer and can interact with intercellular lipids leading to their fluidization [48]. In addition, ethanol imparts fluidity to the liposome bilayers thus increasing their flexibility, which can further enhance their penetration into the skin and eventual release of their contents [31,35]. In this study, ethosomes alone induced only a modest ( 1.8-fold) enhancement of HA penetration compared to that from Ethanol:PBS control, indicating that the observed enhancement cannot be primarily attributed to ethosomes. Incorporation of SPACE peptide on the ethosome surface in the SES formulation enhanced HA penetration by an additional 3 -fold compared to ethosomes alone.

The precise mechanisms by which the SES formulation penetrates into the skin require further investigation. SPACE peptide has been shown to exhibit affinity with keratin and corneocytes [13]. In the present study, the partition coefficient of SPACE peptide between PBS and stratum corneum+epidermis was measured to be $9.8+/-1.5$. The partition coefficient between PBS and dermis was found to be $4.3+/-0.2$. This high partition coefficient of SPACE peptide into epidermis may assist its own penetration as well as that of SES formulation into the skin.

Mechanisms of penetration of ethosomes or other liposomal carriers into skin has received significant attention in the literature [31, 40, 41, 49]. Confocal microscopy studies of human and mouse skin have shown that elasticity of the vesicle bilayer plays an important role in their penetration, with softer vesicles exhibiting deeper penetration compared to rigid vesicles [50]. Freeze-fracture electron microscopy studies have indicated that liposomes adsorb on the stratum corneum and induce detectable changes in the composition of lipids in the lower region of the SC [51]. Interactions of ethosomes with the SC are likely to be more complex due to the presence of ethanol. Ethosomes could potentially enter the SC intact or fuse/break-up upon their contact with the SC. Electron microscopy studies have shown presence of regions of ethosomal lipids interdispersed with the SC lipids, which lead to their disruption and enhanced drug penetration [52]. Such interactions need further exploration. Regardless of the precise mechanisms, SPACE-ethosomes in the SES formulation, or 
fragments thereof, may traverse through the lipids or corneocytes, thereby enhancing HA penetration.

Penetration of HA using the SES formulation exhibited significant dependence on formulation characteristics, specifically $\mathrm{pH}$ and concentration of SPACE peptide. The effect of $\mathrm{pH}$ on penetration of HA from the SES formulation may be attributed to ionization of HA as well as SPACE peptide. HA has a pKa value of about 3.0 [53]. Hence, HA is significantly less ionized at a $\mathrm{pH} 4$ compared to that at $\mathrm{pH} 8$, which may facilitate its penetration. However, this alone does not explain increased transport since $\mathrm{pH}$ had minimal impact on penetration of HA alone (Fig. 4b). The effect of $\mathrm{pH}$ was more pronounced in the presence of ethosomes, which may have originated from the charge on SPACE peptide, which has an isoelectric point of 6 . SPACE peptide has a charge of -1.4 at a $\mathrm{pH}$ of 8 and +1.4 at $\mathrm{pH} 4$ primarily due to histidine. The positive charge may potentially assist in encapsulation of HA and also in penetration into skin. Furthermore, significantly improved HA skin absorption was observed from SES formulation containing $5 \mathrm{mg} / \mathrm{mL}$ of conjugated SPACE-peptide compared to that from ethosomes alone or SES formulation containing $2 \mathrm{mg} / \mathrm{mL}$ of conjugated SPACE-peptide. This dependence likely originates from increased affinity of ethosomes towards skin due to presence of SPACE peptide since the peptide itself was found to exhibit increased affinity towards the SC. Therefore, an increase in the concentration of conjugated SPACE-peptide could lead to the increased interaction between ethosomal particles and skin, and in turn improve dermal absorption of SES formulation. Further increase in the concentration of conjugated SPACE-peptide led to reduced penetration, which may have potentially originated from increased interactions among particles leading to aggregation or the presence of excess unreacted SPACE peptide which could potentially mitigate interactions between ethosomes and skin. Further studies are necessary to investigate these possibilities.

Enhanced penetration using the SES formulation was also observed in vivo in hairless mice. While the formulation enhanced penetration of HA into skin, no significant increase in systemic absorption of HA was observed. Penetration into the skin of hairless inbred mice suggests that the trans-epidermal route, rather than the trans-follicular route, is the primary penetration pathway for HA using this formulation. These in vivo observations are consistent with the in vitro skin penetration results, which further confirmed the ability of our SES formulation ethosomes to deliver HA regardless of the species.

The SES system offers several advantages as a topical drug delivery system. It allows the delivery of macromolecules and has the potential to deliver a wider range of molecules owing to the use of ethosomes. The lipid membrane of ethosomes may allow encapsulation of hydrophobic drugs while the aqueous nature of the interior allows encapsulation of hydrophilic drugs. Further studies should be conducted to determine the efficacy of SES in delivering drugs of various physic-chemical properties. In comparison to device-based technologies, SES offers the advantage of ease-of-use. At the same time, it has certain limitations, primarily the cost associated with peptide-based formulations which is generally higher than chemical-based formulations. Long-time stability of the formulation and its wide range applicability also needs to be demonstrated. 


\section{Conclusions}

The study demonstrates enhanced penetration of HA into skin due to a SPACE-ethosomal based formulation, SES. Significant penetration of HA into stratum corneum and epidermis was observed. Skin penetration of HA was SPACE peptide concentration and $\mathrm{pH}$ dependent. The optimal SPACE peptide concentration was observed to be $5 \mathrm{mg} / \mathrm{mL}$ with an optimal $\mathrm{pH}$ of 4.0. Hyaluronic Acid Penetration of HA was confirmed in vitro in porcine and human skin, and in vivo in hairless mouse skin. The SES formulation containing HA was stable for 28 days at $4^{\circ} \mathrm{C}$. Future studies should focus on developing a detailed understanding of SPACE-ethosome penetration pathways and assessing the utility of SPACE-ethosomes and the SES formulation in aiding transport of additional macromolecules into skin.

\section{Acknowledgments}

This work was supported by Convoy Therapeutics Inc. A.C.A. was supported by a National Science Foundation (NSF) Graduate Research Fellowship under Grant DGE-1144085. Authors acknowledge Dr. Deborah Slee for critically reading and commenting on the manuscript. Confocal Microscopy study was supported by the National Center for Research Resources shared instrumentation Grant 1S10RR022585-01A1. SM is a shareholder and scientific advisor to Convoy Therapeutics.

\section{References}

1. Brown MB, Martin GP, Jones SA, Akomeah FK. Dermal and Transdermal Drug Delivery Systems: Current and Future Prospects. Drug Delivery. 2006; 13:175-187. [PubMed: 16556569]

2. Prausnitz MR, Mitragotri S, Langer R. Current status and future potential of transdermal drug delivery. Nature reviews. Drug discovery. 2004; 3:115-124.

3. Kumar R, Philip A. Modified Transdermal technologies: Breaking the barriers of drug permeation via the skin. Trop J Pharm Res. 2007; 6:633-644.

4. P.R.a.M.o. America. Biopharmaceutical Research Companies Are Developing Nearly 300 Medicines to Treat Diseases of the Skin. Medicines in Development for skin diseases. 2011

5. Cevc G, Vierl U. Nanotechnology and the transdermal routeA state of the art review and critical appraisal. Journal of Controlled Release. 2010; 141:277-299. [PubMed: 19850095]

6. Prausnitz MR, Langer R. Transdermal drug delivery. Nat Biotechnol. 2008; 26:1261-1268. [PubMed: 18997767]

7. Yano T, Nakagawa A, Tsuji M, Noda K. Skin permeability of various non-steroidal antiinflammatory drugs in man. Life Sci. 1986; 39:1043-1050. [PubMed: 3747720]

8. Banga AK. Foreword to transdermal delivery mini focus issue. Ther Deliv. 2012; 3:293-294. [PubMed: 22833988]

9. Kamada H, Okamota T, Kawamura M, Shibata H, Abe Y, Ohkawa A, Nomura T, Sato M, Mukai Y, Sugita T, Imai S, Nagano K, Tsutsumi Y, Nakagawa S, Mayumi T, Tsunoda S. Creation of novel cell-penetrating peptides for intracellular drug delivery using systematic phage display technology originated from tat transduction domain. Biol Pharm Bull. 2007; 30:218-223. [PubMed: 17268054]

10. Kim YC, Ludovice PJ, Prausnitz MR. Transdermal delivery enhanced by magainin pore-forming peptide. Journal of Controlled Release. 2007; 122:375-383. [PubMed: 17628164]

11. Rothbard JB, Garlington S, Lin Q, Kirschberg T, Kreider E, McGrane PL, Wender PA, Khavari PA. Conjugation of arginine oligomers to cyclosporin A facilitates topical delivery and inhibition of inflammation. Nat Med. 2000; 6:1253-1257. [PubMed: 11062537]

12. Sawant R, Torchilin V. Intracellular transduction using cell-penetrating peptides. Mol Biosyst. 2010; 6:628-640. [PubMed: 20237640]

13. Hsu T, Mitragotri S. Delivery of siRNA and other macromolecules into skin and cells using a peptide enhancer. P Natl Acad Sci USA. 2011; 108:15816-15821. 
14. Chen YP, Shen YY, Guo X, Zhang CS, Yang WJ, Ma ML, Liu S, Zhang MB, Wen LP. Transdermal protein delivery by a coadministered peptide identified via phage display. Nat Biotechnol. 2006; 24:455-460. [PubMed: 16565728]

15. Colen S, van den Bekerom MPJ, Mulier M, Haverkamp D. Hyaluronic Acid in the Treatment of Knee Osteoarthritis A Systematic Review and Meta-Analysis with Emphasis on the Efficacy of Different Products. Biodrugs. 2012; 26:257-268. [PubMed: 22734561]

16. Loutradi KE, Tarlatzi TB, Kolibianakis EM, Tarlatzis BC. Does hyaluronan improve embryo implantation? Curr Opin Obstet Gyn. 2008; 20:305-307.

17. Voigt J, Driver VR. Hyaluronic acid derivatives and their healing effect on burns, epithelial surgical wounds, and chronic wounds: A systematic review and meta-analysis of randomized controlled trials. Wound Repair Regen. 2012; 20:317-331. [PubMed: 22564227]

18. Price RD, Berry MG, Navsaria HA. Hyaluronic acid: the scientific and clinical evidence. J Plast Reconstr Aes. 2007; 60:1110-1119.

19. Wiest L, Kerscher M. Native hyaluronic acid in dermatology - Results of an expert meeting. J Dtsch Dermatol Ges. 2008; 6:176-180. [PubMed: 18315621]

20. Goodwin JF, Choi SY. Quantification of Protein Solutions with Trinitrobenzenesulfonic Acid. Clin Chem. 1970; 16 24-\&.

21. Bendas ER, Tadros MI. Enhanced Transdermal Delivery of Salbutamol Sulfate via Ethosomes. Aaps Pharmscitech. 2007; 8

22. Nanda A NS, Khan Ghilzai NM. Current developments using emerging transdermal technologies in physical enhancement methods. Current Drug Delivery. 2006; 3:233-242. [PubMed: 16848725]

23. Particle size analysis - Photon correlation spectroscopy. ISO standard document. 1996; 13321

24. Fang YP, Tsai YH, Wu PC, Huang YB. Comparison of 5-aminolevulinic acid-encapsulated liposome versus ethosome for skin delivery for photodynamic therapy. Int J Pharm. 2008; 356:144-152. [PubMed: 18325699]

25. Karande P, Jain A, Mitragotri S. Relationships between skin's electrical impedance and permeability in the presence of chemical enhancers. Journal of Controlled Release. 2006; 110:307-313. [PubMed: 16313994]

26. Brooke D, Nielsen I, Debruijn J, Hermens J. An Interlaboratory Evaluation of the Stir-Flask Method for the Determination of Octanol-Water Partition-Coefficients (Log Pow). Chemosphere. 1990; 21:119-133.

27. Kligman AM, Christophel E. Preparation of Isolated Sheets of Human Stratum Corneum. Arch Dermatol. 1963; 88 702-\&.

28. Mezei M, Gulasekharam V. Liposomes - a Selective Drug Delivery System for the Topical Route of Administration .1. Lotion Dosage Form. Life Sciences. 1980; 26:1473-1477. [PubMed: 6893068]

29. Mezei M, Gulasekharam V. Liposomes - a Selective Drug Delivery System for the Topical Route of Administration - Gel Dosage Form. J Pharm Pharmacol. 1982; 34:473-474. [PubMed: 6126554]

30. Honeywell-Nguyen PL, Groenink HWW, Bouwstra JA. Elastic vesicles as a tool for dermal and transdermal delivery. J Liposome Res. 2006; 16:273-280. [PubMed: 16952881]

31. Elsayed MMA, Abdallah OY, Naggar VF, Khalafallah NM. Lipid vesicles for skin delivery of drugs: Reviewing three decades of research. International Journal of Pharmaceutics. 2007; 332:116. [PubMed: 17222523]

32. Dubey V, Mishra D, Nahar M, Jain NK. Vesicles as tools for the modulation of skin permeability. Expert Opin Drug Del. 2007; 4:579-593.

33. El Maghraby GMM, Williams AC, Barry BW. Can drug-bearing liposomes penetrate intact skin? J Pharm Pharmacol. 2006; 58:415-429. [PubMed: 16597359]

34. Cevc G, Vierl U. Nanotechnology and the transdermal route: A state of the art review and critical appraisal. Journal of controlled release : official journal of the Controlled Release Society. 2010; 141:277-299. [PubMed: 19850095]

35. Godin B, Touitou E. Ethosomes: New prospects in transdermal delivery. Crit Rev Ther Drug. 2003; 20:63-102. 
36. Godin B, Touitou E. Mechanism of bacitracin permeation enhancement through the skin and cellular membranes from an ethosomal carrier. Journal of controlled release : official journal of the Controlled Release Society. 2004; 94:365-379. [PubMed: 14744487]

37. Ainbinder D, Touitou E. Testosterone ethosomes for enhanced transdermal delivery. Drug delivery. 2005; 12:297-303. [PubMed: 16188729]

38. Touitou E, Dayan N, Bergelson L, Godin B, Eliaz M. Ethosomes - novel vesicular carriers for enhanced delivery: characterization and skin penetration properties. Journal of controlled release : official journal of the Controlled Release Society. 2000; 65:403-418. [PubMed: 10699298]

39. Trotta M, Peira E, Carlotti ME, Gallarate M. Deformable liposomes for dermal administration of methotrexate. International journal of pharmaceutics. 2004; 270:119-125. [PubMed: 14726128]

40. Gillet A, Lecomte F, Hubert P, Ducat E, Evrard B, Piel G. Skin penetration behaviour of liposomes as a function of their composition. European journal of pharmaceutics and biopharmaceutics : official journal of Arbeitsgemeinschaft fur Pharmazeutische Verfahrenstechnik e.V. 2011; 79:4353. [PubMed: 21272638]

41. Elsayed MM, Abdallah OY, Naggar VF, Khalafallah NM. Deformable liposomes and ethosomes: mechanism of enhanced skin delivery. International journal of pharmaceutics. 2006; 322:60-66. [PubMed: 16806755]

42. Uchino T, Lefeber F, Gooris G, Bouwstra J. Physicochemical characterization of drug-loaded rigid and elastic vesicles. International journal of pharmaceutics. 2011; 412:142-147. [PubMed: 21540095]

43. Wo Y, Zhang Z, Zhang Y, Wang D, Pu Z, Su W, Qian Y, Li Y, Cui D. Preparation of ethosomes and deformable liposomes encapsulated with 5-fluorouracil and their investigation of permeability and retention in hypertrophic scar. Journal of nanoscience and nanotechnology. 2011; 11:78407847. [PubMed: 22097495]

44. Brown TJ, Alcorn D, Fraser JR. Absorption of hyaluronan applied to the surface of intact skin. The Journal of investigative dermatology. 1999; 113:740-746. [PubMed: 10571728]

45. Kage M, Tokudome Y, Hashimoto F. Permeation of hyaluronan tetrasaccharides through hairless mouse skin: an in vitro and in vivo study. Arch Dermatol Res. 2013; 305:69-77. [PubMed: 22740084]

46. Pavicic T, Gauglitz GG, Lersch P, Schwach-Abdellaoui K, Malle B, Korting HC, Farwick M. Efficacy of cream-based novel formulations of hyaluronic acid of different molecular weights in anti-wrinkle treatment. Journal of drugs in dermatology : JDD. 2011; 10:990-1000. [PubMed: 22052267]

47. Gariboldi S, Palazzo M, Zanobbio L, Selleri S, Sommariva M, Sfondrini L, Cavicchini S, Balsari A, Rumio C. Low molecular weight hyaluronic acid increases the self-defense of skin epithelium by induction of beta-defensin 2 via TLR2 and TLR4. J Immunol. 2008; 181:2103-2110. [PubMed: 18641349]

48. Bach M, Lippold BC. Percutaneous penetration enhancement and its quantification. Eur J Pharm Biopharm. 1998; 46:1-13. [PubMed: 9700018]

49. Bouwstra JA, Honeywell-Nguyen PL. Skin structure and mode of action of vesicles. Advanced drug delivery reviews. 2002; 54(Suppl 1):S41-S55. [PubMed: 12460715]

50. van Kuijk-Meuwissen ME, Mougin L, Junginger HE, Bouwstra JA. Application of vesicles to rat skin in vivo: a confocal laser scanning microscopy study. Journal of controlled release : official journal of the Controlled Release Society. 1998; 56:189-196. [PubMed: 9801442]

51. Hofland HEJ, Bouwstra JA, Bodde HE, Spies F, Junginger HE. Interactions between Liposomes and Human Stratum-Corneum in-Vitro - Freeze-Fracture Electron-Microscopic Visualization and Small-Angle X-Ray-Scattering Studies. Brit J Dermatol. 1995; 132:853-866. [PubMed: 7662563]

52. Jain S, Tiwary AK, Sapra B, Jain NK. Formulation and evaluation of ethosomes for transdermal delivery of lamivudine. AAPS PharmSciTech. 2007; 8:E111. [PubMed: 18181532]

53. Brown MB, Jones SA. Hyaluronic acid: a unique topical vehicle for the localized delivery of drugs to the skin. J Eur Acad Dermatol. 2005; 19:308-318. 


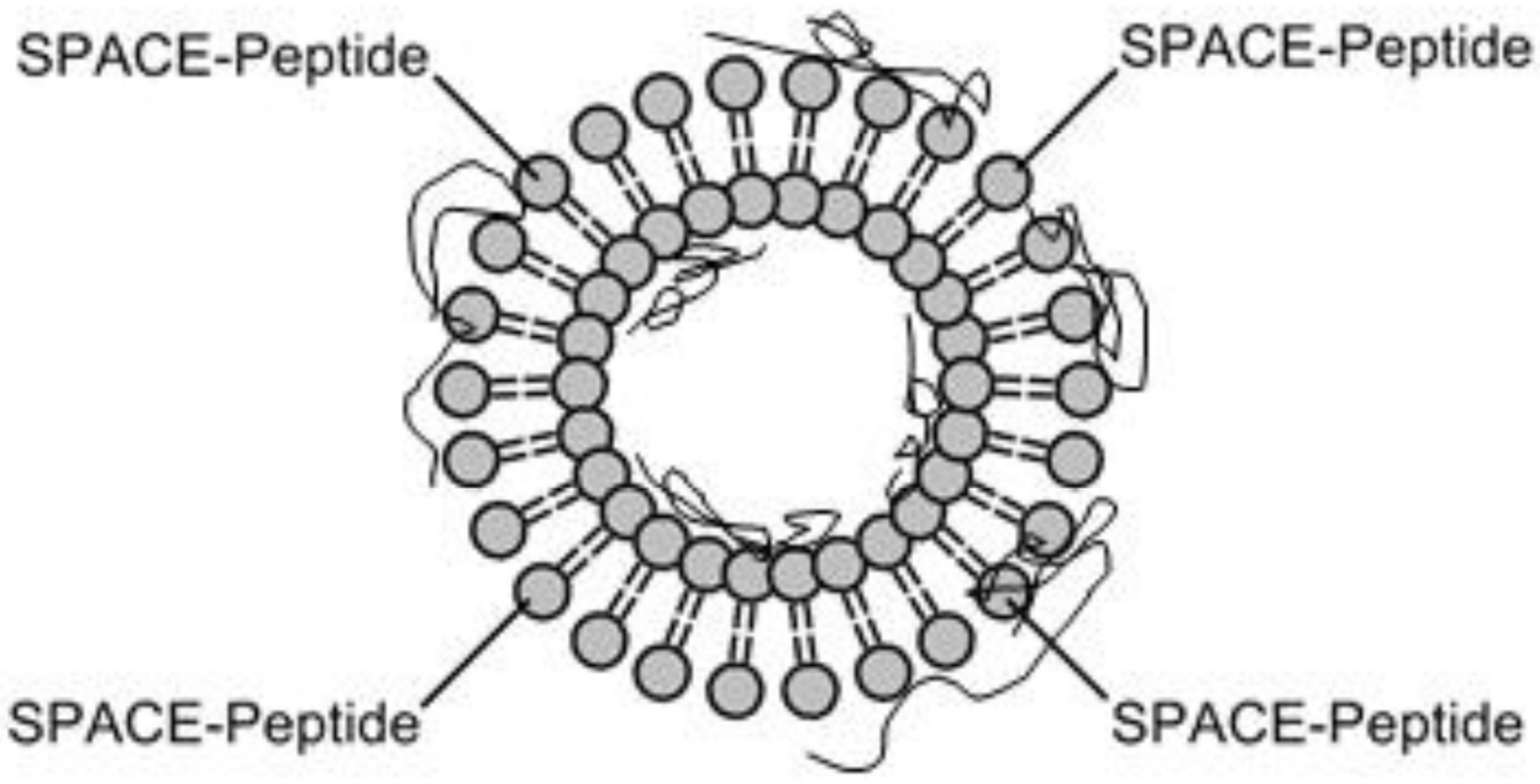

\section{Hyaluronic acid}

Figure 1.

Schematic of an ethosome modified with SPACE peptide conjugated phospholipids used for topical delivery of Hyaluronic Acid (HA). 

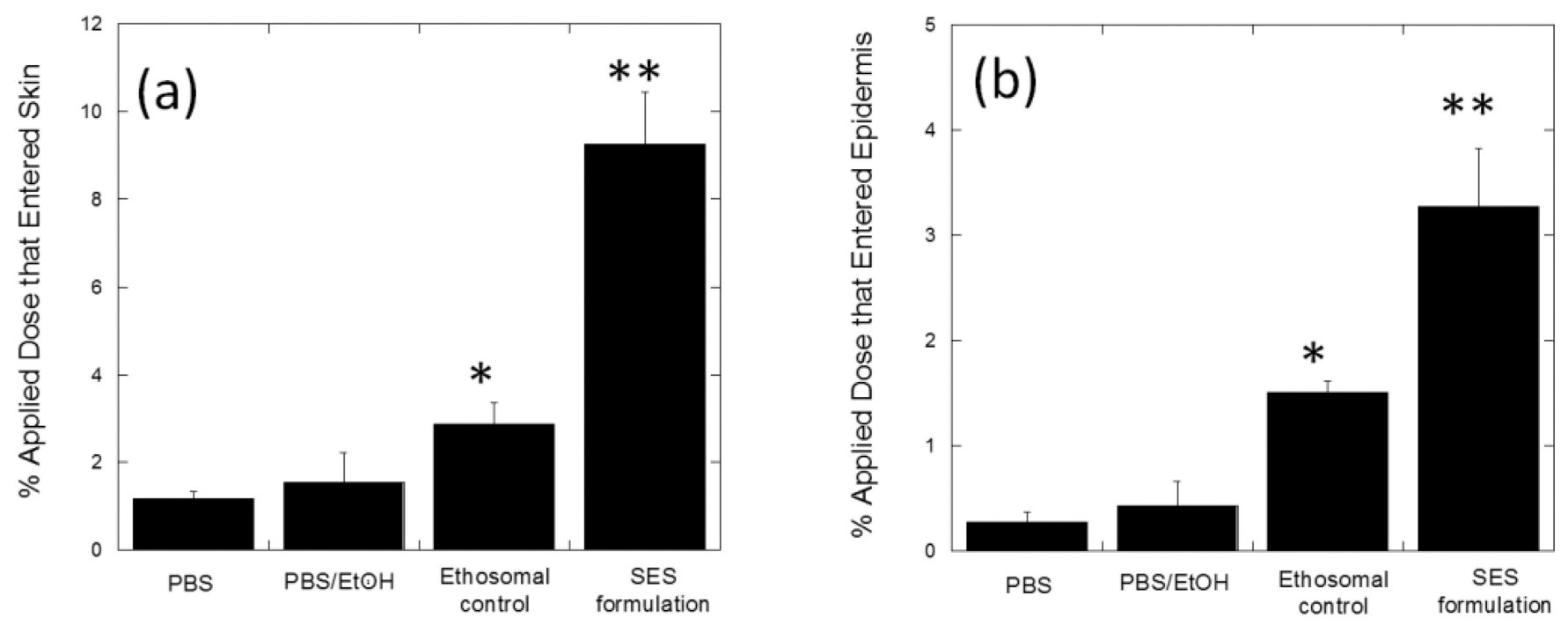

Figure 2.

SES enhances penetration of high molecular weight HA into porcine skin in vitro. (a) Percent penetration of topically applied dose into total skin (b) Percent penetration of topically applied dose into epidermis. SES formulation demonstrated significantly greater total skin (a) $(9.3 \% \pm 1.2 \%, p<0.01$ versus ethosomal control) and epidermal penetration (b) of HA $(3.3 \% \pm 0.6 \%, p<0.01$ versus ethosomal control). PBS: PBS ( $\mathrm{pH} 4.0,50 \mathrm{mM})$ control solution; PBS/EtOH: 45\% v/v mixture of PBS (pH 4.0, $50 \mathrm{mM}$ ) and Ethanol; Ethosomal control: Ethosomes alone at pH 4.0 (without SPACE-peptide surface modification); SES formulation: The SPACE-Ethosomal system formulation with SPACE peptide conjugated phospholipids $(5 \mathrm{mg} / \mathrm{mL})$ at $\mathrm{pH} 4.0$. Values represent mean $\pm \mathrm{SD}(\mathrm{n}=3) *$ Statistically different from PBS group $(p<0.05)$. ** Statistically very different from all other groups $(p<$ $0.01)$. 


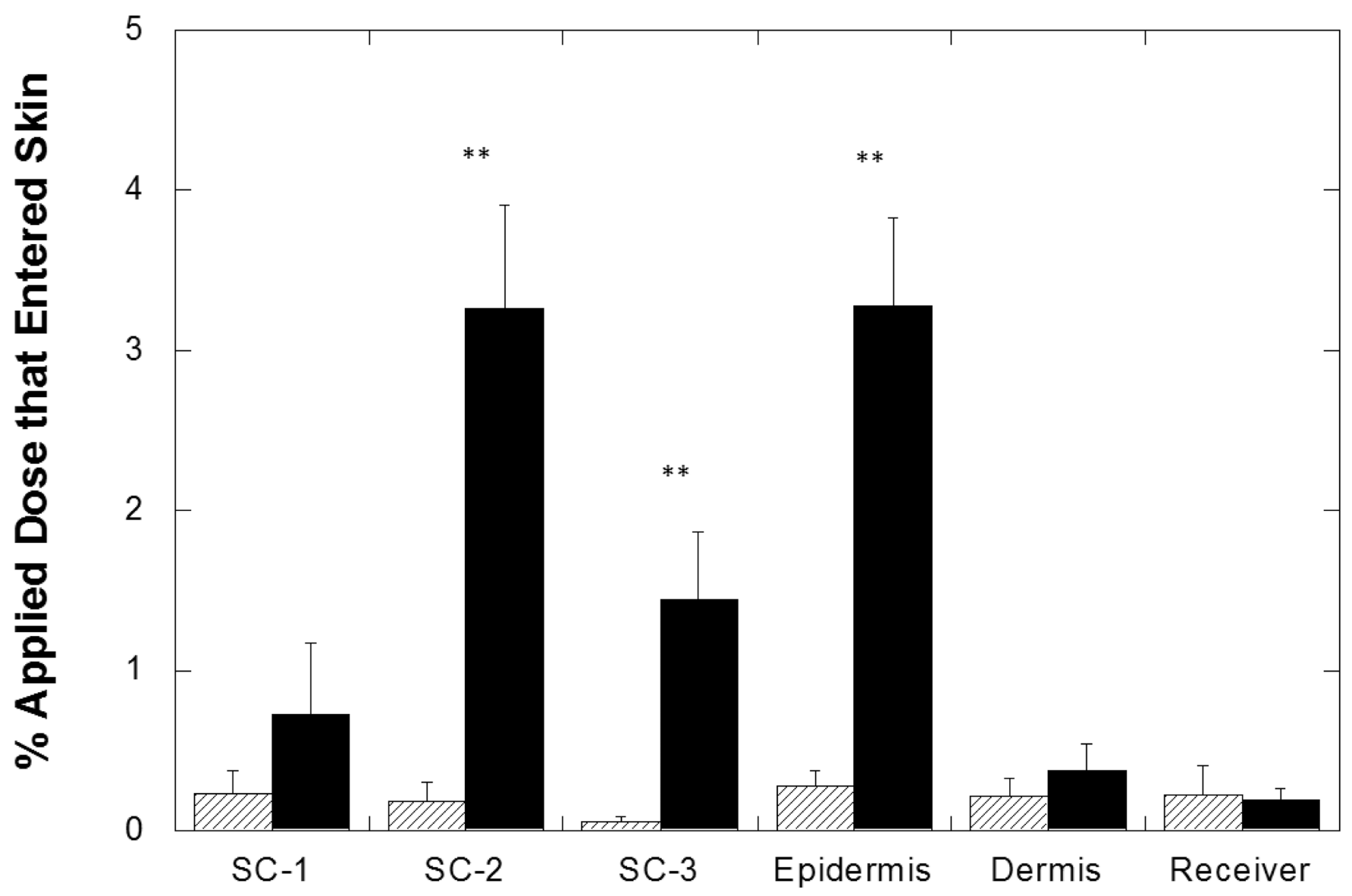

Figure 3.

Enhanced high molecular weight HA penetration into porcine stratum corneum and epidermis using the SES formulation. SES formulation demonstrated significantly enhanced accumulation in SC $(5.4 \% \pm 0.6 \%, p<0.01$ versus PBS control) and in viable epidermis (3.3\% $\pm 0.6 \%, p<0.01$ versus PBS control). Backslash bar: HA from PBS (pH 4.0, $50 \mathrm{mM}$ ) control solution; Solid black bar: HA from SES formulation at $\mathrm{pH}$ 4.0. SC-1 corresponds to $1^{\text {st }}$ strip, SC-2 corresponds to collection of $2^{\text {nd }}$ through $5^{\text {th }}$ strips and SC-3 corresponds to collection of $6^{\text {th }}$ through $10^{\text {th }}$ strips. Values represent mean $\pm \mathrm{SD}(\mathrm{n}=3) * *$ Statistically very different from PBS groups $(p<0.01)$. 

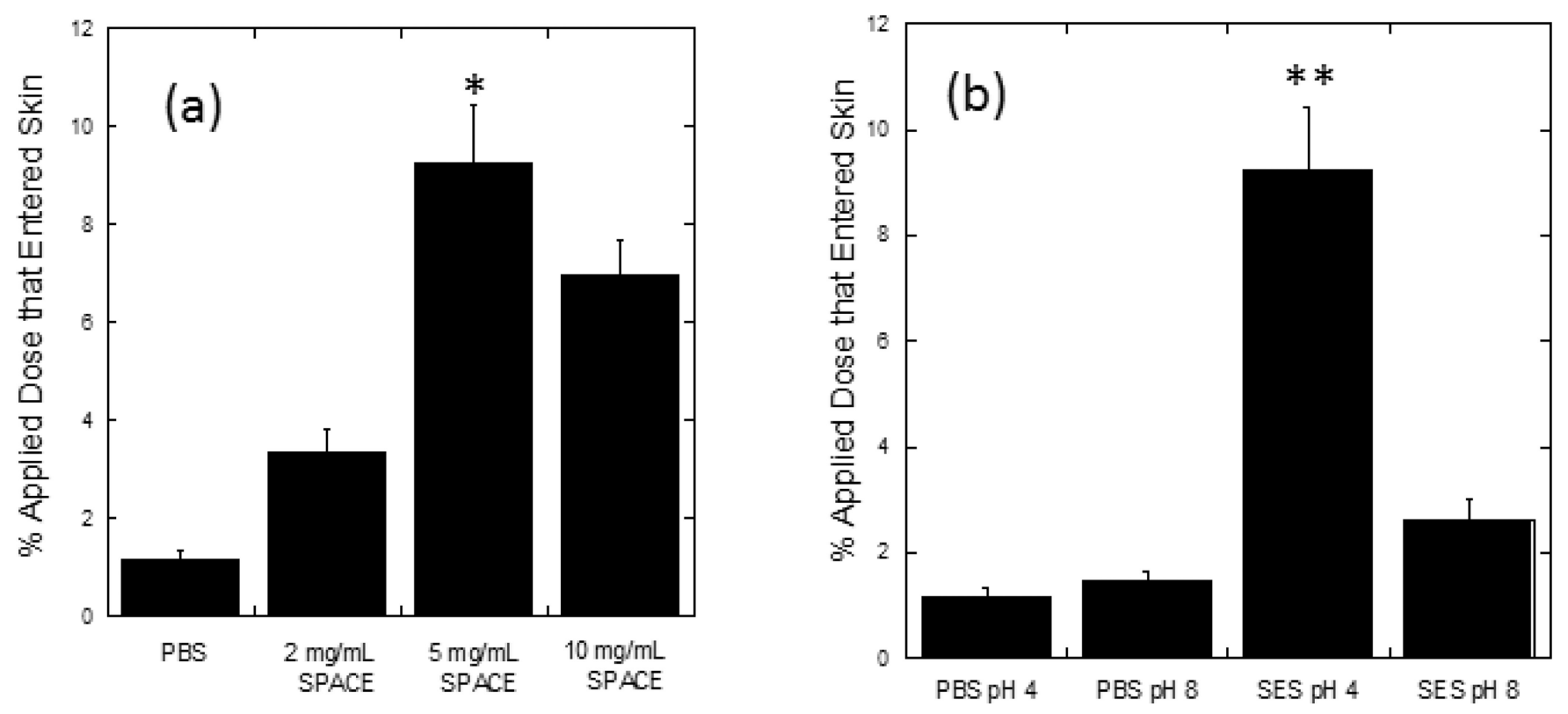

Figure 4.

Penetration of high molecular weight HA into porcine skin is SPACE peptide concentration and $\mathrm{pH}$ dependent. (a) SPACE peptide concentration dependent penetration and (b) $\mathrm{pH}$ dependent penetration. All formulations contain $1 \mathrm{mg} / \mathrm{mL}$ HA. (a) PBS: PBS (pH 4.0, 50 $\mathrm{mM}$ ) solution; $2 \mathrm{mg} / \mathrm{mL}$ SPACE: The SPACE-ethosomal system formulation with SPACE peptide conjugated phospholipids $(2 \mathrm{mg} / \mathrm{mL})$ at $\mathrm{pH} 4.0 ; 5 \mathrm{mg} / \mathrm{mL}$ SPACE: The SPACEethosomal system formulation with SPACE peptide conjugated phospholipids $(5 \mathrm{mg} / \mathrm{mL})$ at pH 4.0; 10 mg/mL SPACE: The SPACE-ethosomal system formulation with SPACE peptide conjugated phospholipids $(10 \mathrm{mg} / \mathrm{mL})$ at $\mathrm{pH} 4.0$. (b) $\mathrm{PBS} \mathrm{pH} 4: \mathrm{PBS}$ (pH 4.0, 50 $\mathrm{mM}$ ) solution ( $1 \mathrm{mg} / \mathrm{mL})$; PBS $\mathrm{pH}$ 8: PBS (pH 8.0, $50 \mathrm{mM})$ solution; SES pH4: The SPACE-ethosomal system formulation with SPACE peptide conjugated phospholipids (5 $\mathrm{mg} / \mathrm{mL}$ ) at $\mathrm{pH} 4.0$; SES pH8: The SPACE-ethosomal system formulation with SPACE peptide conjugated phospholipids $(5 \mathrm{mg} / \mathrm{mL})$ at $\mathrm{pH}$ 8.0. Values represent mean $\pm \mathrm{SD}(\mathrm{n}=3)$ $*$ Statistically different from all other groups $(p<0.05)$. **Statistically very different from all other groups $(p<0.01)$. 


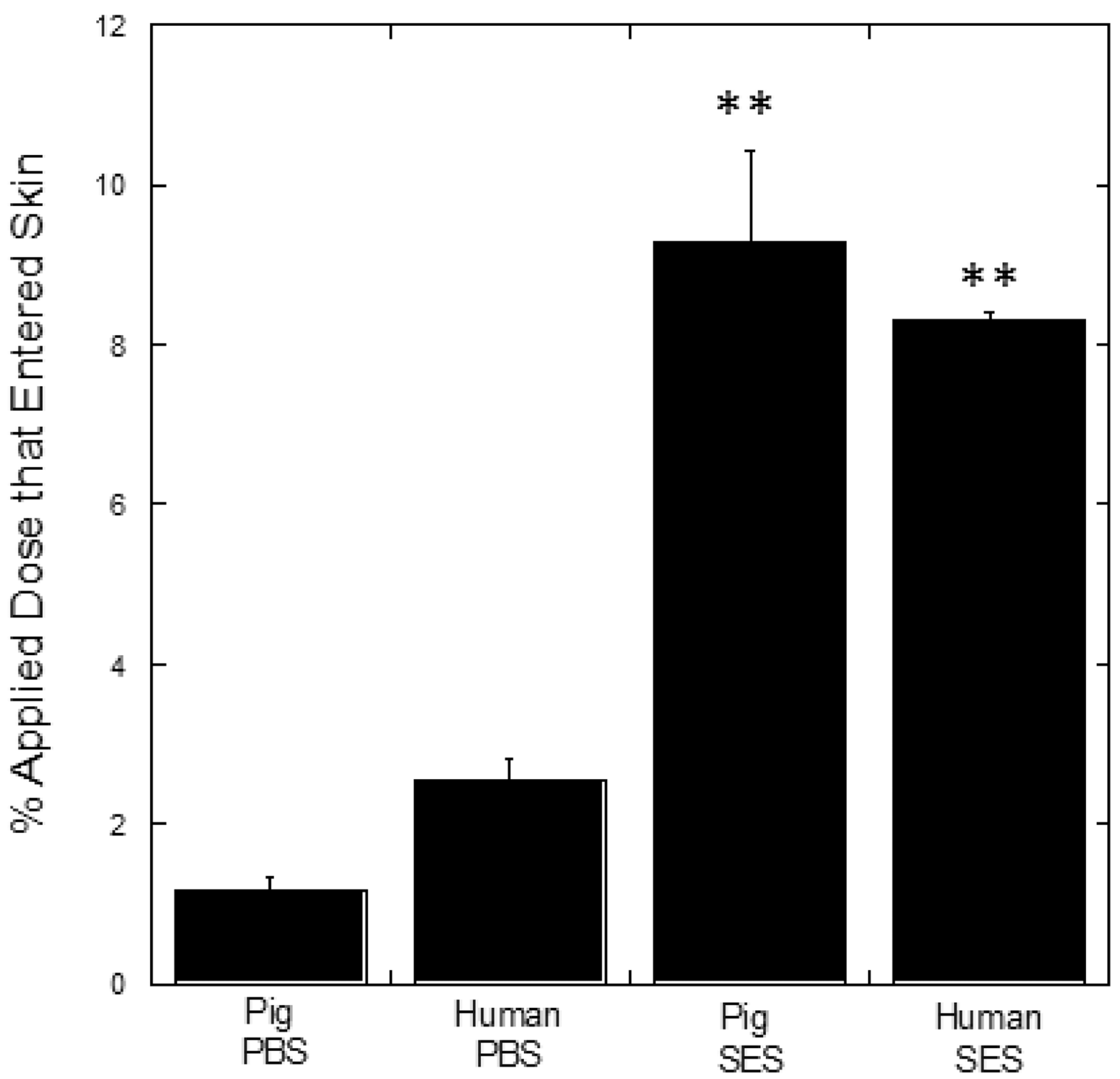

Figure 5.

SES enhances penetration of high molecular weight HA in human and pig skin in vitro. All formulations contain $1 \mathrm{mg} / \mathrm{mL}$ HA. Pig PBS: PBS (pH 4.0, $50 \mathrm{mM}$ ) solution applied on pig skin; Human PBS: PBS (pH 4.0, $50 \mathrm{mM}$ ) solution applied on human skin; Pig SES: The SPACE-Ethosomal system formulation with SPACE peptide conjugated phospholipids (5 $\mathrm{mg} / \mathrm{mL}$ ) at pH 4.0 applied on pig skin; Human SES: The SPACE-ethosomal system formulation with SPACE peptide conjugated phospholipids $(5 \mathrm{mg} / \mathrm{mL})$ at $\mathrm{pH} 4.0$ applied on human skin. Values represent mean $\pm \mathrm{SD}(\mathrm{n}=3) * *$ Statistically very different from PBS groups $(p<0.01)$. 
(a)

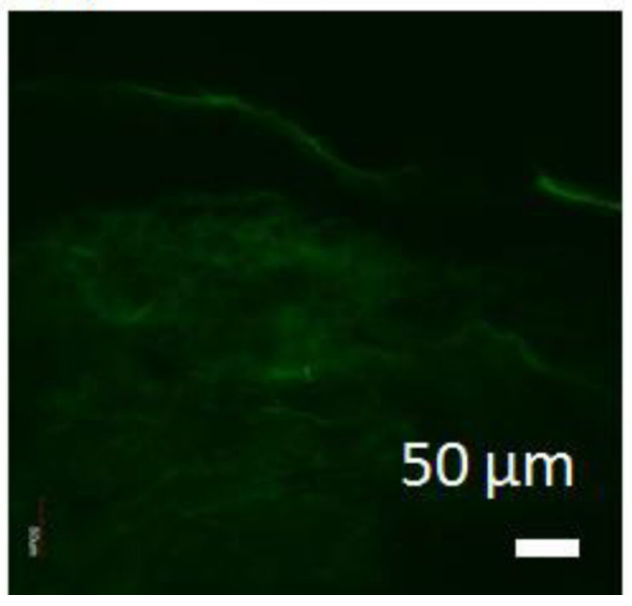

Figure 6.

SES enables penetration of high molecular weight HA into dermis of human skin in vitro. (a) Confocal image of skin penetration of HA from PBS (pH 4.0) solution; (b) Confocal image of skin penetration of HA from the SPACE-ethosomal system formulation with SPACE peptide conjugated phospholipids ( $5 \mathrm{mg} / \mathrm{mL}$ )at $\mathrm{pH}$ 4.0. (c) Zoom-in confocal image of HA accumulated in dermis from (b). 
(a)
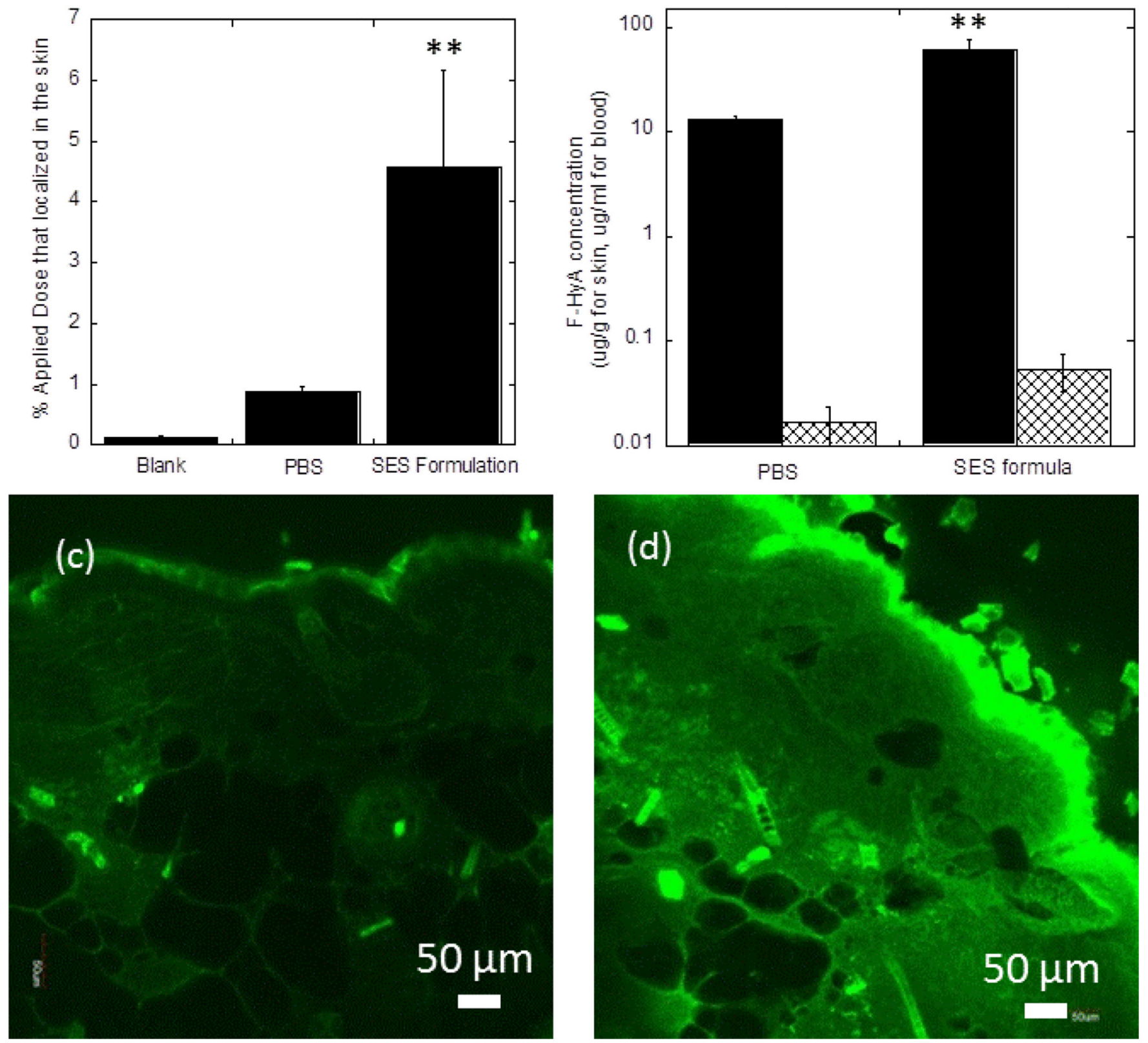

Figure 7.

SES enhances penetration of high molecular weight HA into SKH1-hr hairless skin in vivo (a) Dermal absorption of HA from SES formula compared to its control group. (b) Comparison of the concentration of HA in skin tissue and in systemic circulation from SES formula ( $\mathrm{pH} 4.0$ ) and PBS (pH 8.0). Control PBS of $\mathrm{pH} 8$ was chosen due to its proximity to neutral $\mathrm{pH}$ which provides a natural reference point to assess potential adverse effects of SES formulation on skin. For details of the effect of pH on HA delivery see Figs. $4 \mathrm{~b}$ and 6. Solid black bar: HA concentration in mouse skin; Crosshatch bar: HA concentration in mouse blood. (c) Confocal image of skin penetration of HA from PBS; (d) confocal image 
of skin penetration of HA from SES formula. All formulations contain $1 \mathrm{mg} / \mathrm{mL}$ HA. Blank: untreated mice skin. PBS: PBS (pH 8.0) solution; SES formula: SPACE-ethosomal system formulation with SPACE peptide conjugated phospholipids $(5 \mathrm{mg} / \mathrm{mL})$ at $\mathrm{pH} 4.0$. Values represent mean $\pm \operatorname{SD}(n=4)$. $* *$ Statistically very different from PBS group $(p<0.01)$. 
(a)

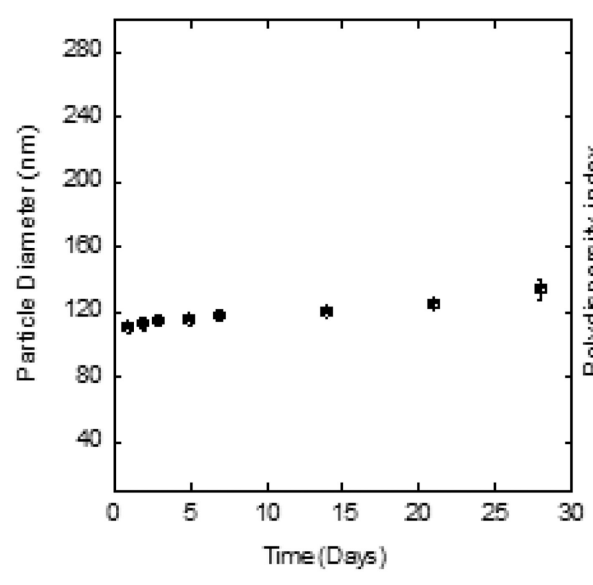

(b)

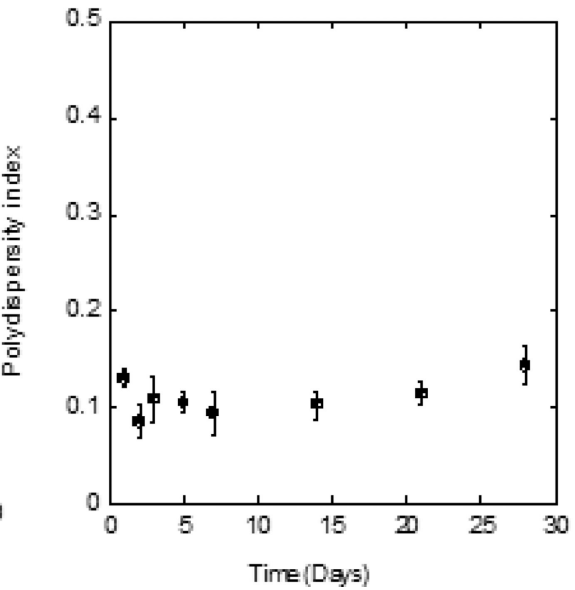

(c)

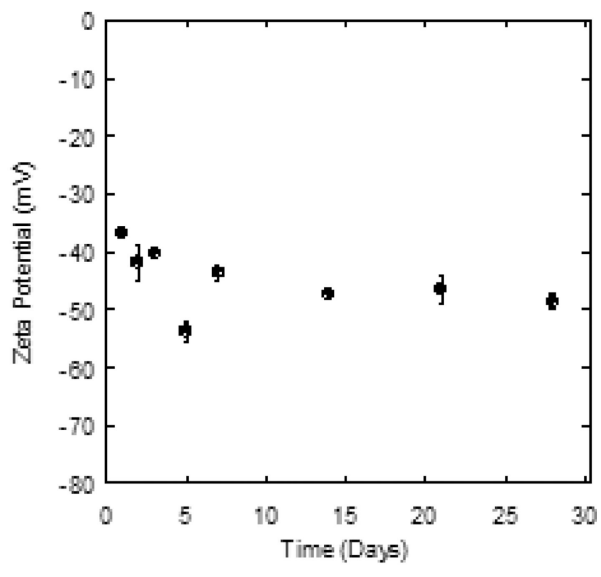

Figure 8.

Stability of SES HA formulations ( $\mathrm{pH} 4$ ). (a,b) Particle size distribution of SPACEethosomes as a function of time at $4^{\circ} \mathrm{C}$; (c) $\zeta$-potential of SPACE-ethosomes as a function of time at $4^{\circ} \mathrm{C}$. 